\title{
RATTLESNAKE NUISANCE REMOVALS AND URBAN EXPANSION IN PHOENIX, ARIZONA
}

\author{
Steven L. Pitts ${ }^{1}$, Bryan D. Hughes ${ }^{2}$, and Ivana Mali1,3
}

\begin{abstract}
Urbanization can have significant consequences on local wildlife. While some species can thrive in urban environments, others are often seen as nuisance animals and therefore are either killed by landowners or removed by professionals. Snakes, especially rattlesnakes, represent one such taxon. Here, we analyzed rattlesnake removal data from the city of Phoenix, Arizona, USA, to determine whether the removal data directly correlates with urban expansion. Between 2011 and 2014, over 500 rattlesnakes and over 300 non-rattlesnakes were removed by professionals, with significant removal clusters in the northern Phoenix metropolis. Land cover change analyses showed that all removal sites experienced dramatic changes in the past decade. There was a significant increase in urban land cover and significant decrease in shrub land cover, suggesting a negative impact of urbanization on local snakes.
\end{abstract}

RESUMEN.-La urbanización puede tener consecuencias significativas en la fauna local. Mientras algunas especies pueden prosperar en ambientes urbanos, otras normalmente son vistas como molestias y son exterminadas por los dueños de las tierras, o son removidas por profesionales. Las serpientes, especialmente las cascabeles, representan uno de estos taxa. En este estudio analizamos datos de remociones de cascabeles de la ciudad de Phoenix, Arizona, EUA para determinar si las remociones se correlacionan directamente con la expansión urbana. Durante los años 2011 al 2014 más de 500 cascabeles y 300 no-cascabeles fueron removidas por profesionales, donde los lugares con más abundancia de animales fueron al norte de la metrópolis de Phoenix. El análisis de uso de la tierra muestra que todos los sitios de donde las especies fueron removidas han sufrido cambios drásticos en la última década. Ha habido un crecimiento significativo en el área utilizada para urbanización, en contraste con el área cubierta de vegetación, lo que sugiere un impacto negativo de la urbanización en las especies de serpientes locales.

Urbanization is one of the most dramatic forms of land transformation which has profound influences on local species abundance, diversity, and composition (Cam et al. 2000, DeStefano and DeGraaf 2003, Marchetti et al. 2006). Some fauna are known to use humanaltered and human-occupied areas, tolerating and even thriving in an urban environment, as anthropogenic environments can offer abundant clusters of artificial resources, such as garbage and vegetable gardens (Beckmann and Lackey 2008, Grubbs and Krausman 2009, Goddard et al. 2010, Lowry et al. 2013). There is substantial evidence that urban development can subsidize some wildlife populations (Kristan et al. 2004, Boarman et al. 2006) and that human activities can create new, complex, and often poorly understood trophic dynamics in wildlife communities (Faeth et al. 2005). For example, artificial water supplementation can lead to an increase in water-dependent desert fauna (Coe and Rotenberry 2003). Consequently, large predators can be attracted to human-associated prey items, yet urban association can significantly increase their mortality rates (Moss et al. 2016).

Research on the effects of urbanization in the American Southwest has mostly focused on birds and mammals, and only recently have studies begun to evaluate effects of urbanization on herpetofauna. Yet, arid regions of the United States have particularly diverse lizard and snake assemblages. Ackley et al. (2015) found that lizard diversity and abundance can be negatively affected by man-made structures but positively affected by urban parks. Some lizard species can persist in small patches of appropriate habitat (Sullivan and Sullivan 2008), while others can become locally extinct in the absence of prey species (Sullivan et al. 2014). Road construction is known to increase snake road mortality (Jones et al. 2011), and Sullivan et al. (2017) found that desert preserves near metropolitan areas have lower snake species richness in

\footnotetext{
${ }^{1}$ Department of Biology, Eastern New Mexico University, 1500 S Ave. K, Portales, NM.

${ }^{2}$ Rattlesnake Solutions, LLC, Phoenix, AZ

${ }^{3}$ Corresponding author. E-mail: ivana.mali@enmu.edu
} 

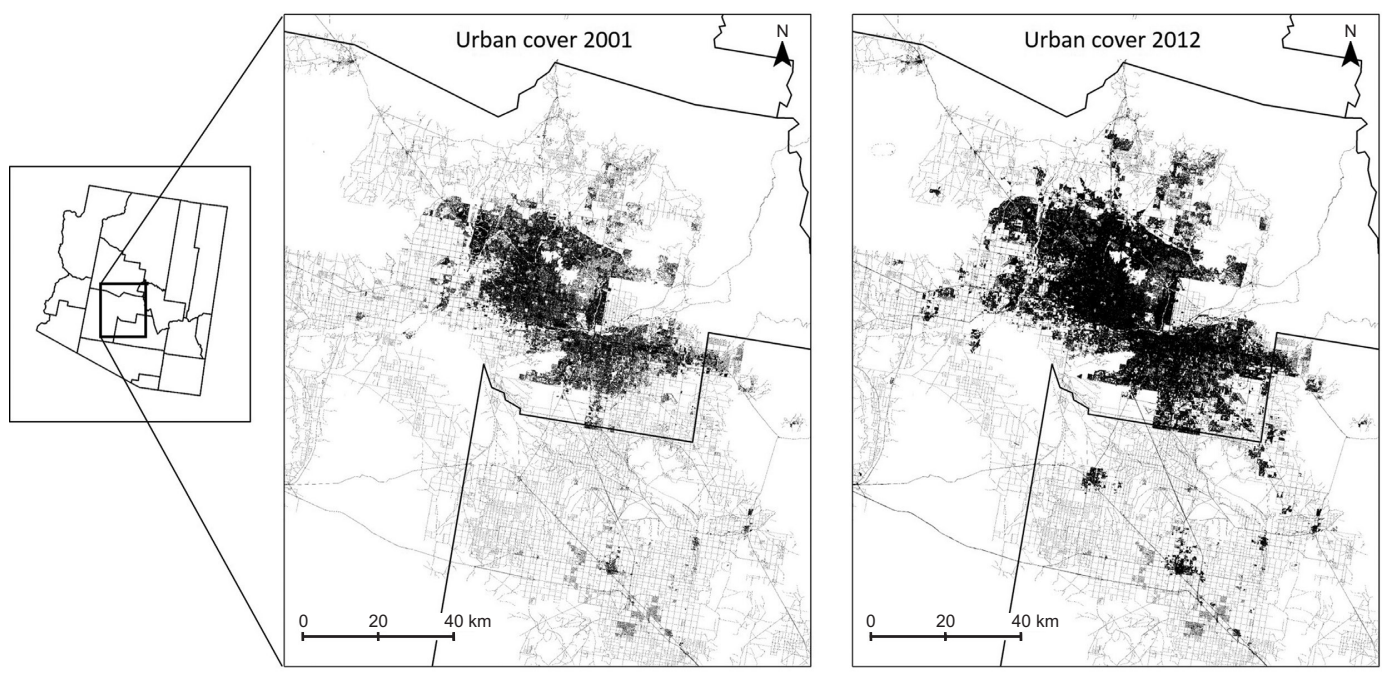

Fig. 1. Maps of Arizona counties (left) and the Phoenix metropolitan area in 2001 (middle) and 2012 (right), depicting urban land cover expansion in an 11 year span.

comparison to preserves more distant from metropolitan areas.

Survivorship of wildlife in urban settings often depends on people's attitudes towards the species, as well as safety concerns. Nuisance species found in areas where they are not wanted by humans is a growing wildlife management problem (Nowak et al. 2002, Sullivan et al. 2015, Menkhorst et al. 2016). Often, problem animals are either translocated or killed by landowners (Warburton and Norton 2009). Snakes, especially rattlesnakes, are often seen as nuisance animals in urban environments and can raise concerns due to their toxic venom and cryptic coloration. Rattlesnakes are known to find refuge in and around urban and suburban residential areas and this behavior can increase human-rattlesnake encounters (Laidig and Golden 2004). In areas where human-rattlesnake interactions are inevitable, intentional and accidental snake mortalities can happen (Bonnet et al. 1999, McCrystal and Ivanyi 2011).

Arizona has one of the most diverse rattlesnake assemblages in the United States (Crother et al. 2012). At least 6 rattlesnake species are known inhabitants of Phoenix and the surrounding suburbs: western diamondbacked rattlesnake (Crotalus atrox), southwestern speckled rattlesnake (C. mitchellii pyrrhus), northern black-tailed rattlesnake $(C$. molossus molossus), tiger rattlesnake (C. tigris),
Sonoran sidewinder (C. cerastes cercobombus), and Mohave rattlesnake (C. scutulatus). The Phoenix metropolitan area is one of the fastest growing areas in the United States, gaining over 1.3 million residents since 2000 and having an estimated 4,574,351 residents today. The Phoenix metropolitan area has been expanding by acquiring and developing land in outlying wild areas (Fig. 1), and this practice suggests that human encounters with snakes are inevitable. In this study, we explored whether human-snake encounters are the outcomes of urban expansion into surrounding wilderness. We used spatial data from professional snake removals provided by a local Phoenix snake removal agency in order to (1) determine where snake removals are most common and (2) determine if the removal areas correlated with a land use shift from shrub vegetation cover to urban cover, which includes housing and road developments. Due to particularly negative attitudes toward venomous snakes, we primarily focused on rattlesnakes (genus Crotalus), but for comparative purposes we also analyzed nonvenomous snakes (family Colubridae).

\section{Methods}

We used 2011-2014 snake removal data from Rattlesnake Solutions, LLC (Phoenix, AZ). We converted each removal locality (resident 
TABLE 1. Rattlesnakes removed from the Phoenix metropolitan area by Rattlesnake Solutions, LLC, from 2011 to 2014.

\begin{tabular}{lc}
\hline Species & Number removed (\%) \\
\hline Crotalus atrox & $435(85.1)$ \\
Crotalus mitchellii pyrrhus & $38(7.4)$ \\
Crotalus scutulatus & $23(4.5)$ \\
Crotalus tigris & $7(1.4)$ \\
Crotalus molossus molossus & $4(0.8)$ \\
Crotalus cerastes cercobombus & $4(0.8)$ \\
TOTAL & 511 \\
\hline
\end{tabular}

address) into GPS coordinates (WGS 84). We used the Optimized HotSpot Analysis tool in ArcMap 10.2.2 (ESRI 2012) to visually represent snake removal clusters. This tool takes the snake removal point data and aggregates the incidents into weighted features. Using the distribution of the weighted features, the tool identifies an appropriate scale of analysis. It calculates a Getis-Ord Gi* statistic for each feature in the data set by looking at each feature within the context of neighboring features, where $Z$ scores and $P$ values indicate where features with high or low values cluster spatially. Significant results occur when the local sum is very different from the expected local sum, and when that difference is too large to be the result of random chance.

To examine the land cover change, we downloaded 2001 and 2012 vegetation cover layers from LANDFIRE Geospatial Data (Rollins and Frame 2006), where the 2012 layer represents land cover at the time of the removal and the 2001 layer represents the historic land cover. Because the majority of the removal data came from years 2012 and 2013, we felt it was most appropriate to use 2012 vegetation cover as a representation of recent land cover. These layers contain over 20 land cover types. For simplicity, we reclassified both layers to create the following land cover classes: shrub, urban, urban vegetation, tree, herbaceous, crop, and other (Supplementary Material 1). We created 1-km buffers around each removal site. We then mapped the buffers to 2012 and 2001 land cover, and used the isectpolyrst tool in Geospatial Modeling Environment 0.7.3 software (Beyer 2012) to calculate the percent land cover within each buffer for each year. Rattlesnake movement patterns differ among species and between sexes (i.e., Schuett et al. 2013, Clark et al. 2014). Because the majority of snake removals
Table 2. Colubrid snakes removed from the Phoenix metropolitan area by Rattlesnake Solutions, LLC, from 2011 to 2014.

\begin{tabular}{lc}
\hline Species & Number removed (\%) \\
\hline Pituophis catenifer & $231(70.2)$ \\
Hypsiglena chlorophaea & $28(8.5)$ \\
Lampropeltis getula & $21(6.4)$ \\
Coluber flagellum & $20(6.1)$ \\
Rhinocheilus lecontei & $17(5.2)$ \\
Sonora semiannulata & $5(1.5)$ \\
Salvadora hexalepis & $2(0.6)$ \\
Thamnophis cyrtopsis & $2(0.6)$ \\
Tantilla sp. & $1(0.3)$ \\
Chionactis occipitalis & $1(0.3)$ \\
Trimorphodon sp. & $1(0.3)$ \\
ToTAL & 329 \\
\hline
\end{tabular}

in Phoenix were western diamond-backed rattlesnakes, we based the size of the buffer on the typical movement distances for this species, which usually do not exceed $1.6 \mathrm{~km}$ (Schuett et al. 2016). We compared percent land cover within each buffer between the years 2001 and 2012 by performing a Wilcoxon's signed-ranks test. We focused on 2 land cover classes: shrub and urban, which represented the majority of land cover within the buffers we examined $(73 \%-88 \%)$. We hypothesized that our snake removal sites likely represent recently urbanized areas that have encroached into natural snake habitat, where snakes potentially remained despite alterations. We also hypothesized that 2012 would have a significantly higher proportion of urban land cover compared to 2001. We inferred statistical significance at $\alpha=0.05$ and created boxplots to visually represent the data. We conducted statistical analyses using program R (version 3.2.3; R Core Team 2013).

\section{Results}

Five-hundred and eleven rattlesnakes were removed between 2011 and 2014, with western diamond-backed rattlesnake accounting for 435 removals $(85 \%$; Table 1$)$. In comparison, 329 non-rattlesnakes (colubrids) were removed during the same period, with gopher snake (Pituophis catenifer) accounting for 231 removals $(70 \%$; Table 2$)$. Some removals were not reported with a precision that could yield exact GPS coordinates. Such localities consisted of $<3 \%$ of the overall data set and were excluded from further analyses. Significant rattlesnake clusters were found in northeastern 

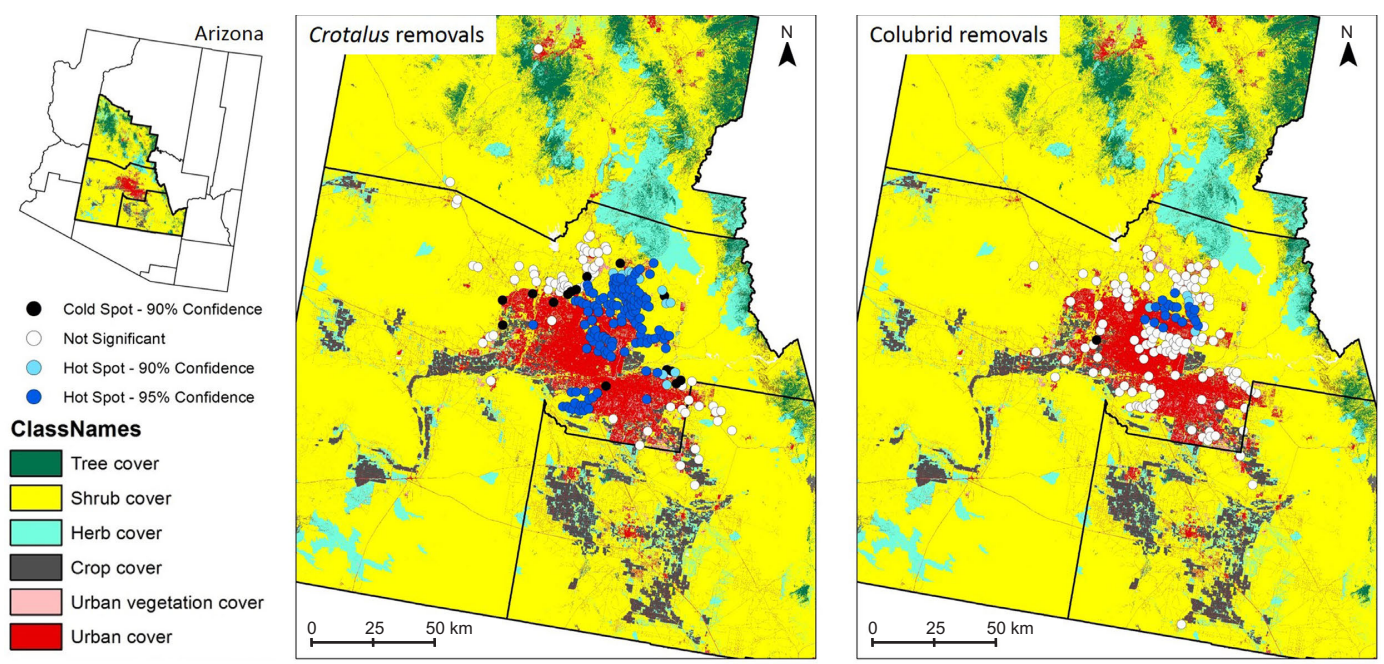

Fig. 2. Maps of Arizona counties specifically showing vegetation cover types in and around the Phoenix metropolitan area (top left), and visual representation of rattlesnake (Crotalus spp.; middle) and nonvenomous snake (colubrids; right) removal clusters using Optimized HotSpot analyses in ArcMap (Esri, Redlands, CA).

Phoenix, with some clusters in central and southern Phoenix (Fig. 2). The non-rattlesnake removal regions greatly overlapped with rattlesnake removals, but the Hotspot analysis for colubrids revealed fewer clusters and only in northern Phoenix (Fig. 2).

Land cover change boxplots for each snake group showed dramatic shifts from 2001 to 2012 (Fig. 3). There was a significant urban land cover increase from $17 \%$ to $40 \%$ at rattlesnake removal sites $(P<0.001)$ and from $27 \%$ to $54 \%$ at non-rattlesnake removal sites $(P<$ $0.001)$ in the 11-year period. By contrast, shrub land cover significantly decreased from $66 \%$ to $48 \%$ at rattlesnake removal sites $(P<0.001)$ and from $45 \%$ to $31 \%$ at non-rattlesnake removal sites $(P<0.001)$. Although both shifts were significant, the increase in urbanization was more dramatic than the decrease in surrounding shrub land (Fig. 3).

\section{Discussion}

Southwestern, arid regions of the United States have been subject to drastic urbanization for the past century. Urbanization has profound effects on wildlife that can cause significant and often complex alterations in wildlife community structure. Given the particularly diverse reptilian assemblages in the Southwest and the scarce assessment of herpetofauna, especially snakes, in urban settings
(Sullivan et al. 2017), it is important to address impacts of urbanization on this vertebrate group. This paper sought to document humansnake encounters in the Phoenix metropolitan area by analyzing the spatial data of snake removals provided by a professional snake removal agency. We also sought to assess land cover change at snake removal sites. Our data show high numbers of snake removals in a relatively short time period. Generally, rattlesnakes were more often removed than nonvenomous snakes but it remains unclear whether this is due to higher abundances of rattlesnakes or to greater fear of rattlesnakes. Non-rattlesnakes are less threatening and therefore reported numbers could be biased low.

Overall, we found an uneven snake community, a result that has previously been reported by researchers who surveyed snake communities near Phoenix. Specifically, Sullivan et al. (2017) surveyed snake communities on Cave Buttes, the largest and most disturbed urban preserve on the northeastern edge of the Phoenix metropolitan area. Overall, they reported 15 species of snakes, and the majority of snake encounters were with western diamond-backed rattlesnakes (59\%). Dominance of diamond-backed rattlesnakes has also been reported by others who surveyed sites within the Chihuahuan and Sonoran Deserts (Mendelson and Jennings 1992, Jones 

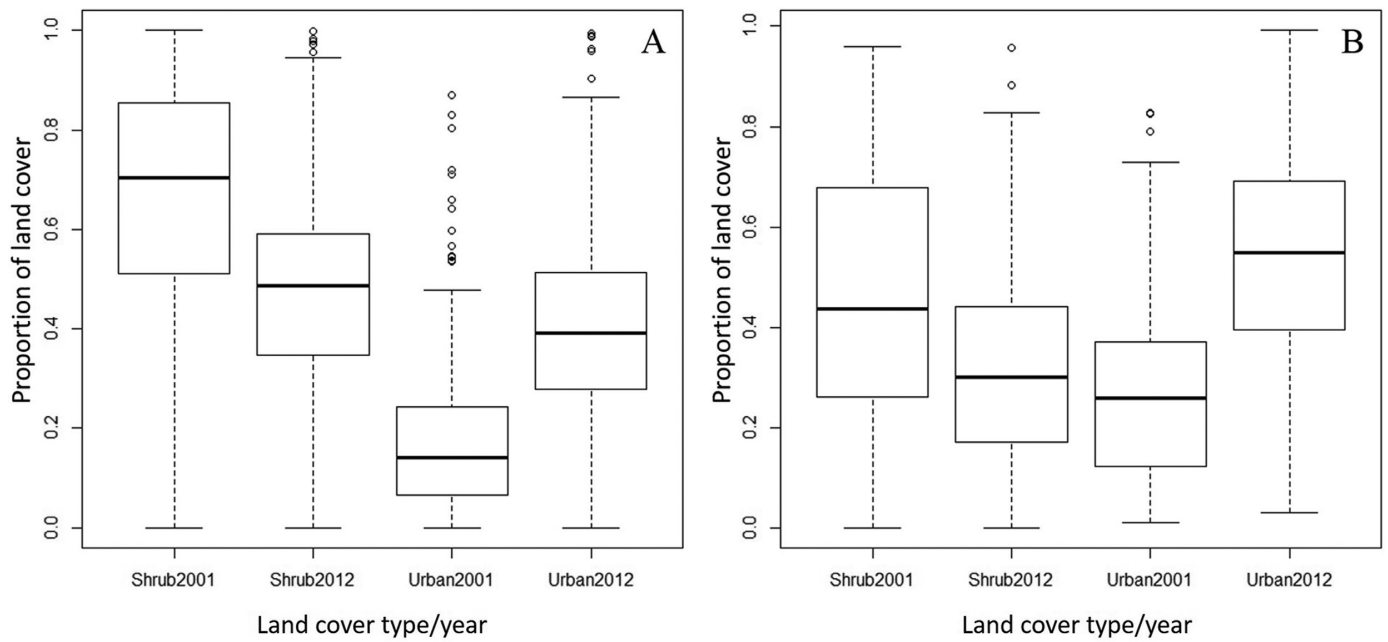

Fig. 3. Boxplots representing the percent shrub land cover and urban land cover in 2001 and 2012 within the 1-km buffers around snake removals in and around Phoenix, Arizona: A, rattlesnake removal buffer areas; B, nonvenomous snake removal buffer areas.

et al. 2011), but not at the magnitude reported by our study or Sullivan et al. (2017). The increase in lagomorphs, one of the main prey items of C. atrox, in metropolitan areas of the Southwest has been a suggested explanation for their high occurrence (Sullivan et al. 2017). Interestingly, the most commonly encountered colubrid in our study was the gopher snake (28\% of all snake removals); however, this species comprised only $5 \%-7 \%$ of snakes reported in other surveys conducted in and around Phoenix (Jones et al. 2011, Sullivan et al. 2017). It is generally found that $P$. catenifer is not a common species within Sonoran Desert communities, but here we point out this may not hold true in urban outskirts. It is possible that like C. atrox, $P$. catenifer is attracted to the high abundance of lagomorphs and rodents in urbanized areas.

Overall, our data show that snake removal sites were historically less urbanized, suggesting that human encroachment (i.e., new neighborhoods and housing developments) induces human-snake encounters. Although Phoenix has been expanding in all directions in the past decade (Fig. 1), our data show that snake removals were not uniformly distributed along the Phoenix periphery. This does not necessarily indicate that there is a disparity in snake abundances across the Phoenix metropolitan area, but we do speculate that the abundances are truly low in highly urbanized areas of central Phoenix. One possibility for the observed clustering in northeastern Phoenix is due to that area being called a "favored quarter" for housing, a term brought on by resorts and the tourist hotspot of Scottsdale (Rex 2000). This area is also close to mountain preserves, such as Cave Buttes. Affluent areas are likely to increase and maintain plant species richness, which attracts various wildlife (Ackley et al. 2015). Ackley et al. (2015) noted a strong positive relationship between affluent areas of Phoenix (i.e., high median income) and lizard diversity. However, homeowners likely have more control of, and negative attitudes toward, snakes, and therefore may be willing to invest in expensive snake removal services. For example, Rattlesnake Solutions, LLC, charges $\$ 200$ per visit, which may be unaffordable by less affluent homeowners. This could potentially explain why there was a lack of removals in southern and southwestern portions of Phoenix, which are mainly surrounded by agricultural areas (i.e., croplands). It is also possible that in rural, lower-income areas, homeowners are more prone to killing snakes or removing snakes themselves instead of paying for expensive services. In addition, Rattlesnake Solutions, LLC, is not the only entity that provides snake removal services in Phoenix. For example, the Phoenix Fire Department conducts snake removals at no cost. Unfortunately, our requests to obtain data from additional snake removal entities were denied. Therefore, our visual 
representation of the encounters across Phoenix does not include all removals, but we feel it is a good representation of how urban expansion and the "luxury effect" can induce mitigation translocations.

Mitigation translocation of venomous reptiles has become a common practice in southwestern metropolises (Nowak et al. 2002, Sullivan et al. 2004, Massei et al. 2010, Sullivan et al. 2015). While mitigation translocation aims to resolve human-animal conflict, such practices can be shortsighted and often overlook the complexity of potential impacts (Menkhorst et al. 2016). Mitigation translocation has been criticized as often poorly planned with little follow-up (Menkhorst et al. 2016). Recent studies on mitigation translocations showed little success in 3 species of herpetofauna, including western diamondbacked rattlesnakes, in the Phoenix metropolitan area (Sullivan et al. 2004, 2015, Kwiatkowski et al. 2008). For example, depending on the distance of translocation, animals either returned to the site of capture or experienced higher risk of predation due to increased rates of movement across unfamiliar terrain (Sullivan et al. 2015). All snakes in our data set were successfully captured without injuries, but the spatial information on translocation sites was not kept. Anecdotally, we know that snakes from our study were released to the closest suitable habitat that contained drainage systems and cool areas for aestivation and these sites were located 0.5 to $3 \mathrm{~km}$ away from the removal sites. Therefore, we speculate that many snakes returned to the site of capture, which is not a long-term solution to the human-snake conflict.

Conservation of natural resources in human-dominated landscapes remains a challenge, especially in the case of less favorable taxa like rattlesnakes. Human-snake conflict in Phoenix became particularly worrisome when the Arizona legislature proposed that residents be allowed to shoot snakes in their yards with small-caliber guns (Arizona House Bill 2022), which not only endangers the snakes but can also cause human safety concerns due to increased use of firearms. Scientists, natural resource managers, and private translocation agencies should work together with the public to develop the best possible strategies to overcome human-snake conflicts and reduce negative impacts on snake populations. We encourage a bottom-up approach of educating the public on the important roles snakes play in desert ecosystems and safe practices of avoiding snakes in general. Furthermore, we suggest that snake removal entities in Phoenix collaborate with researchers to track and monitor translocated snakes in order to improve their practices. Given the generally short distances between removal and translocated sites in our data set, it is crucial to confirm or dispute that nearby drainage sites with hibernacula provide long-term local refuge for the snakes. Recent research suggests that more emphasis should be given to species behavior, in addition to habitat heterogeneity and microhabitat (see review by Germano et al. 2014). We further recommend development of simulated translocation experiments that incorporate both animal behavior and environmental variables to provide a priori evaluation of translocation success (Ebrahimi et al. 2015).

\section{SupPlementary Materials}

One online-only supplementary file accompanies this article (scholarsarchive.byu.edu/ wnan/vol77/iss3/3).

Supplementary Material 1. Different vegetation land cover classes used by LANDFIRE. For simplicity, we reclassified the original land cover types to fit the needs of the manuscript.

\section{ACKNOWLEDGMENTS}

We thank 2 reviewers and the associate editor for their comments and improvements to the manuscript. We also thank all snake enthusiasts who continue to educate the public on the importance of snakes.

\section{Literature Cited}

Ackley, J.W., J. Wu, M.J. Angilletta JR., S.W. Myint, and B. Sullivan. 2015. Rich lizards: how affluence and land cover influence the diversity and abundance of desert reptiles persisting in an urban landscape. Biological Conservation 182:87-92.

Beckmann, J.P., And C.W. LaCKey. 2008. Carnivores, urban landscapes, and longitudinal studies: a case history of black bears. Human-Wildlife Conflicts $2: 168-174$.

BEYER, H.L. 2012. Geospatial modeling environment (version 0.7.2.1). Spatial Ecology LLC. http://www.spatial ecology.com/gme

Boarman, W.I., M.A. Patten, R.J. Camp, and S.J. Collis. 2006. Ecology of a population of subsidized predators: Common Ravens in the central Mojave Desert, California. Journal of Arid Environments 67:248-261. 
Bonnet, X., G. Naulleau, and R. Shine. 1999. The dangers of leaving home: dispersal and mortality in snakes. Biological Conservation 89:39-50.

Cam, E., J.D. Nichols, J.R. Sauer, J.E. Hines, and C.H. FLATHER. 2000. Relative species richness and community completeness: birds and urbanization in the Mid-Atlantic States. Ecological Applications 10: 1196-1210.

Clark, R.W., G.W. Schuett, R.A. Repp, M. Amarello, C.F. Smith, and H.W. Herrmann. 2014. Mating systems, reproductive success, and sexual selection in secretive species: a case study of the western diamond-backed rattlesnake, Crotalus atrox. PLOS ONE 9:e90616.

Coe, S.J., And J.T. Rotenberry. 2003. Water availability affects clutch size in a desert sparrow. Ecology 84:3240-3249.

Crother, B.I., J. Boundy, T.F. Burbrink, J.A. Campbell, K. De Queiroz, D.R. Frost, D.M. Green, R. Highton, J.B. Iverson, and F. Kraus, et al. 2012. Scientific and standard English names of amphibians and reptiles of North America north of Mexico, with comments regarding confidence in our understanding. 7th edition. SSAR Herpetological. Circulars No. 39.

DeStefano, S., and R.M. DeGraaf. 2003. Exploring the ecology of suburban wildlife. Frontiers in Ecology and the Environment 1:95-101.

Ebrahimi, M., E. Ebrahimie, and C.M. Bull. 2015. Minimizing the cost of translocation failure with decision-tree models that predict species' behavioral response in translocation sites. Conservation Biology 29:1208-1216.

[ESRI] Environmental Systems Research Institute. 2012. ArcGIS Release 10.1. Redlands, CA.

Faeth, S.H., P.S. Warren, E. Shochat, and W.A. MarusSICH. 2005. Trophic dynamics in urban communities. AIBS Bulletin 55:399-407.

Germano, J., J.G. Ewen, H. Mushinsky, E. McCoy, and L. Ortiz-Catedral. 2014. Moving towards greater success in translocations: recent advances from the herpetofauna. Animal Conservation 17:1-3.

Goddard, M.A., A.J. Dougill, and T.G. Benton. 2010. Scaling up from gardens: biodiversity conservation in urban environments. Trends in Ecology and Evolution 25:90-98.

GRubbs, S.E., AND P.R. KRAusman. 2009. Use of urban landscape by coyotes. Southwestern Naturalist 54:1-12.

Jones, T.R., R.D. Babb, F.R. Hensley, C. LiWanPo, and B.K. Sullivan. 2011. Sonoran Desert snake communities at two sites: concordance and effects of increased road traffic. Herpetological Conservation and Biology 6:61-71.

Kristan, W.B., III, W.I. Boarman, and J.J. Crayon. 2004. Diet composition of Common Ravens across the urban-wildland interface of the West Mojave Desert. Wildlife Society Bulletin 32:244-253.

Kwiatkowski, M.A., G.W. Schuett, R.A. Repp, E.M. NoWAK, AND B.K. SUlLIVAN. 2008. Does urbanization influence the spatial ecology of Gila monsters in the Sonoran Desert? Journal of Zoology 276:350-357.

Laidig, K.J., AND D.M. Golden. 2004. Assessing timber rattlesnake movements near a residential development and locating new hibernacula in the New Jersey Pinelands. Unpublished Report, Pinelands Commission, New Lisbon, NJ
LOWRY, H., A. LILl, AND B. Wong. 2013. Behavioral responses of wildlife to urban environments. Biological Reviews 88:537-549.

Marchetti, M.P., J.L. Lockwood, AND T. Light. 2006. Effects of urbanization on California's fish diversity: differentiation, homogenization and the influence of spatial scale. Biological Conservation 127: 310-318.

Massei, G., R.J. Quy, J. Gurney, and D.P. Cowan. 2010. Can translocations be used to mitigate human-wildlife conflicts? Wildlife Research 37:428-439.

McCrystal, H.K., and C.S. IVANYI. 2011 Translocation of venomous reptiles in the Southwest: a solution-or part of the problem? Pages 395-402 in W.K. Hayes, K.R. Beaman, M.D. Cardwell, and S.P. Bush, editors, The biology of rattlesnakes. Loma Linda University Press, Loma Linda, CA.

Mendelson, J.R., III, And W.B. Jennings. 1992. Shifts in relative abundance of snakes in a desert grassland. Journal of Herpetology 26:38-45.

Menkhorst, P., N. Clemann, And J. Sumner. 2016. Faunarescue programs highlight unresolved scientific, ethical and animal welfare issues. Pacific Conservation Biology 22:301-303.

Moss, W.E., M.W. Alldredge, and J.N. Pauli. 2016. Quantifying risk and resource use for a large carnivore in an expanding urban-wildland interface. Journal of Applied Ecology 53:371-378

NowaK, E.M., T. Hare, and J. McNally. 2002. Management of "nuisance" vipers: effects of translocation on western diamond-backed rattlesnakes (Crotalus atrox). Biology of the Vipers 2002:533-560.

R CORE TEAm. 2013. R: a language and environment for statistical computing. R Foundation for Statistical Computing, Vienna, Austria. ISBN 3-900051-07-0. http://www.R-project.org

REX, T.R. 2000. Development of metropolitan Phoenix: historical, current and future trends. Center for Business Research, L. William Seidman Research Institute, College of Business, Arizona State University, Phoenix, AZ.

Rollins, M.G., and C. Frame. 2006. The LANDFirE prototype project: nationally consistent and locally relevant geospatial data for wildland fire management. General Technical Report RMRS-GTR-175, USDA Forest Service Rocky Mountain Research Station, Fort Collins, CO.

Schuett, G.W., R.A. Repp, M. Amarello, and C.F. Smith. 2013. Unlike most vipers, female rattlesnakes (Crotalus atrox) continue to hunt and feed throughout pregnancy. Journal of Zoology 289:101-110.

Schuett, G.W, R.A. Repp, C.L. Spencer, K.R. Beaman, AND C.W. PAINTER. 2016. Western diamond-backed rattlesnake (Crotalus atrox). Pages 333-394 in G.W. Schuett, M.J. Feldner, C.F. Smith, and R.S. Reiserer, editors, Rattlesnakes of Arizona. Eco Publishing, Rodeo, NM.

Sullivan, B.K., M.A. Kwiatkowski, and G.W. Schuett. 2004. Translocation of urban Gila monsters: a problematic conservation tool. Biological Conservation 117:235-242.

Sullivan, B.K., D.J. LeavitT, and K.O. Sullivan. 2017. Snake communities on the urban fringe in the Sonoran Desert: influences on species richness and abundance. Urban Ecosystems 20:199-206. 
Sullivan, B.K., E.M. Nowak, and M.A. KwiatKowski. 2015. Problems with mitigation translocation of herpetofauna. Conservation Biology 29:12-18.

Sullivan, B.K., AND K.O. Sullivan. 2008. Common chuckwalla (Sauromalus ater) populations in the Phoenix metropolitan area: stability in urban preserves. Herpetological Conservation and Biology 3:149-154.

Sullivan, B.K., K.O. Sullivan, D. Vardukyan, and T. SumINSKI. 2014. Persistence of horned lizards (Phrynosoma spp.) in urban preserves of central Arizona. Urban Ecosystems 17:707-717.

Warburton, B., And B.G. NorTon. 2009. Towards a knowledge-based ethic for lethal control of nuisance wildlife. Journal of Wildlife Management 73:158-164.

Received 12 December 2016 Accepted 2 August 2017 Published online 5 September 2017 